\title{
A Contrastive Study of Two Versions of Contract Law of the PRC from the Semantic and Communicative Perspective
}

\author{
Ying Qin \\ College of International Exchange of Wuzhou University, Wuzhou, Guangxi 543002, China \\ Email: luoyulinlan@163.com,313575077@qq.com
}

Keywords: Legal Document Translation, Contrastive Study, Semantic and Communicative Translation, Contract Law of the PRC

\begin{abstract}
The whole world is considered as being closely connected as a small village and as being economically, socially, and politically interdependent. In this modern world, having an intimate knowledge of international law and introducing Chinese laws to overseas become more and more imperative. Therefore, legal translation has played an undeniably significant role in the advances made in international cooperation and business negotiation.

By reviewing previous researches, the author finds that scholars have already delved into the field of the legal documents translation guided by the theories of Eugene Nida's dynamic equivalence theory ${ }^{[2]}$ and Susan Sarcevic's communicative theory ${ }^{[3]}$ and so on. No one has applied Newmark's semantic translation and communicative translation principle to the Chinese-English translation of legal texts.

This thesis approaches the topic of a contrastive study of two versions of Contract Law of the PRC from the perspective of Newmark's semantic and communicative translation theory. The present author tentatively explore the subject by making a contrastive study of two versions (Law Press China and the official website of Ministry of Commerce of the People's Republic of China) of Contract Law of the PRC, with a view to comparing which version is better.
\end{abstract}

\section{Introduction}

Ever since China advance the Belt and Road Initiative, it is becoming more and more important and urgent to have an intimate knowledge of the international law and introducing our country's laws to overseas in order to cope with the deepening and widening opening up to the outside world. So the translation of Chinese legal texts plays a major role as a medium of foreign trade and legal communication. From then on, the research of legal language has drawn more and more attention from scores of people.

Thanks to the endeavors of many scholars and researchers, legal language researches have ushered in a new epoch. Compared to other fields of translation, domestic academic study in this field, however, does not belong to a majority. Researches mainly focus on the micro study of legal translation, i.e. lexicon, syntax, and stylistic features. Without a correct understanding of the nature of legal translation, they may produce some seemingly "accurate" translation but actually not faithful or equivalent to the original text (Chen., 1998:47). Until now, people do not have a comprehensive, unanimous, and scientific understanding of legislative translation. Chen Jiong pointed out: "current scholarship on the topic of legal language research is still not so much as some areas of traditional research, and some problems still exist. For example, research on the system of legal language still needs improving and achievements in different branches of legal language research haven't maintained balance among themselves and so on.” (Chen, 2000:14) So it is still necessary for scholars to do more researches on legal language translation both theoretically and practically.

From the angle of semantic translation and communicative translation, the present author will attempt to discuss how to translate legal English effectively. On the basis of linguistic features of 
legal English and criterion for legal document translation, the present author tentatively explores the subject by making a contrastive study of two versions of Contract Law of the People's Republic of China, with a view to comparing which version is better and finding solutions to numerous problems arising from the translation of legislative documents.

\section{A Review of Semantic and Communicative Translation}

Peter Newmark is a highly skilled translation theory master as well as an accomplished translator. In his work Approaches to Translation, Newmark creates semantic translation and communicative translation as two methods of translation. Semantic translation regards to literal meaning of the original text while communicative translation regards much more to the reaction and involvement of receptors. This may results from his noncompliance with Nida's assumption that: "All kinds of translations are to achieve communicating effect, and the most basic rule of any translation is to achieve 'equivalent effect'." For Newmark, the success of equivalent effect is "illusory”. However, the spread could perhaps be reduced when the terms we talked about were substituted as follows:

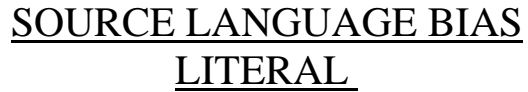

\section{LITERAL}

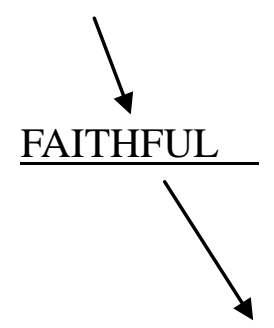

TARGET LANGUAGE BIAS FREE

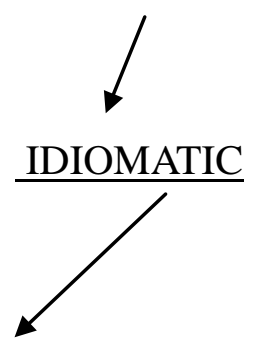

\section{SEMANTIC/COMMUNICATIVE}

In theory, semantic method differs from communicative translation. Semantic translation attempts to restore the original and transfer all the text meaning and sentence structures to the target language as allowed. Communicative translation commits itself to giving its second readers an understanding as close as possible to that obtained on the original readers by converting foreign elements into its own culture (Newmark, 1981:54).

As a result, every word has to be delivered, deviates in language and function marked, and as much tending paid to the message-hence the semantic aspect; however, the organized formats, syntactic aspects as well as the target language, should attach importance to dispose of documents which are to be effective in the target language at the same time - thus the communicative aspect. Legal texts about information only should translated by semantic method. (Newmark, 1981:50). Mere semantic or communicative translation cannot fulfill the task of translating, so we should appropriately combine them in different situations.

\section{A Comparative Study of Two Versions of Contract Law of the PRC}

In modern society, globalization has been the general trend of the world, and none of nations in this world can or would like to hide themselves out of this trend. Having an intimate knowledge of international law and introducing our country's laws to overseas nations become more and more important and urgent to cope with the deepening and widening opening up to the outside world. So the translation of Chinese laws into English plays a major role in foreign trade and legal communication. Thanks to many linguists and scholars, there are two different Chinese-English translation versions of Contract Law of the People's Republic of China. One is from Law Press China (LPC) ${ }^{[7]}$; the other is from Ministry of Commerce of the People's Republic of China (MC) ${ }^{[4]}$. Both of them are authoritative English translation versions, since there is only one Chinese version, so the present author thinks that it is necessary for her to make a tentative study by making a contrastive study of two versions of Contract Law of the People's Republic of China, with a view to 
finding which one is better for readers to use, which is not only academically necessary but also empirically significant.

\subsection{A Comparative Study of Two Versions on Lexical Aspect}

\subsubsection{Legal synonyms}

Ex:

LPC: Article 52

A contract is invalid under any of the following circumstances:

(4) harm is done to social and public interests; or

......

(see Contract Law of the PRC Article52, p.28)

MC: Article 52

A contract shall be null and void under any of the following circumstances:

......

(4) damaging the public interests;

(see Contract Law of the PRC Article52, p.8)

According to Black's law dictionary (1979), semantically, "public" means that "affecting the people or community as a whole", and "public interest" stands for the whole community which contains social interests. If translate Chinese version to "social and public interests", it is against the spirit of communicative translation which commits itself to giving its readers an understanding as close as possible to that obtained on the original readers by converting foreign elements into its own culture and eliminate repetition and tautology. So, according to Newmark's communicative translation theory, it should be translated into "the public interests". And, therefore, MC is more concise than LPC.

\subsubsection{Archaic words}

Ex:

LPC: The parties to a foreign-related contract may choose those laws applicable to the settlement of contract disputes, unless stipulated otherwise by law. If the parties to a foreign-related contract fail to make such choice, the State laws most closely related contract shall apply. (see Contract Law of the PRC Article126, p.62)

MC: Article 126

Parties to a foreign-related contract may select the applicable law for resolution of a contractual dispute, except as otherwise provided by law. Where parties to the foreign-related contract fail to select the applicable law, the contract shall be governed by the law of the country with the closest connection thereto. (see Contract Law of the PRC Article126, p.21)

In contrast to the LPC, "thereto" in MC is an archaic word meaning "to that contract" is much more accurate and serious. As the present author mentioned before, using adequate and appropriate archaism in legislative documents can improve the precision and seriousness of the texts. Moreover, Newmark thought that the semantic translation tends to be more detail and more concentrated, and in the quest of the original. Since "thereto" can bring an effect of original and highlight the preciseness, so, I consider MC is much better.

\subsubsection{Loan words}

Ex:

LPC: Article 47

The counterpart may urge the legal agent to give ratification within one month. Where the legal agent dose not respond, the non-response shall be deemed a refusal of ratification. Pending the ratification, the bona fide counterpart has the right to rescind. The rescission shall be made by a notice. (see Contract Law of the PRC Article47, p.23) 


\section{MC: Article 47}

The counterpart may urge the statutory agent to ratify the contract within one month. It shall be regarded as a refusal of ratification that the statutory agent does not make any expression. A bona fide counterpart has the right to withdraw it before the contract is ratified. The withdrawal shall be made by means of notice. (see Contract Law of the PRC Article47, p.7)

Both of the LPC and MC use a Latin word "bona fide" which semantically means "denotes sincere, honest intention or belief, regardless of the outcome of an action". In English, it equals to "good faith". Using Latin word "bona fide" to express correct Chinese version is more precise and concise than using "good faith".

\subsubsection{Precision and formal words}

Ex:

LPC: Article 326

If the right to use or transfer of a service-related technological result belongs to a legal person or any other organization, the legal person or that organization may conclude a technology contract on the said service-related technological result. (see Contract Law of the PRC Article326, p.142)

MC: Article 326

Where the right to use and the right to transfer job-related technology belong to a legal person or an organization of any other nature, the legal person or organization may enter into a technology contract in respect of such job-related technology. (see Contract Law of the PRC Article326, p.48)

In both British and American law, Chinese version is accepted to translate into "artificial person" or "juristic person", which "has a legal name and has rights, protections, privileges, responsibilities, and liabilities under law, just as natural persons do." So, both semantically and communicatively, we should adhere to "juristic person" or "artificial person" standing for the Chinese version.

\subsection{A Comparative Study of Two Versions on Syntactic Aspect}

\subsubsection{Modal auxiliaries}

Ex:

LPC: Article 8

A legally executed contract has legal binding force on the parties. The parties shall fulfill their obligations as contracted, and may not unilaterally modify or terminate the contract. (see Contract Law of the PRC Article8, p.10)

MC: Article 8

A lawfully established contract shall be legally binding on the parties thereto, each of whom shall perform its own obligations in accordance with the terms of the contract, and no party shall unilaterally modify or terminate the contract. (see Contract Law of the PRC Article8, p.1)

From the perspective of semantic translation, the first "shall” in MC is not appropriate. "shall” is compulsory indicating obligations which equals to Chinese version. But here the sentence does not show any obligations. Although "shall" is widely used in legal texts, we cannot misuse it here. As for the last "shall" here, the present author should point out what Chen Zhongcheng has said: "Translators should use 'may', if a right or authority is conferred by the law; if it is removed, they should employ 'may not'; Translators should use 'shall not', if a responsibility to act is compulsive. The translators should avoid making mistakes by using 'shall' to exercise a right when the receptor serves as the subject of a sentence with an active voice.” (Chen, 1998:37) So, the present author suggests the last "shall” in MC should be replaced by "may" like in LPC.

\subsubsection{Nominalization}

Ex:

LPC: Article 70

If a creditor splits, merges or changes domicile without notifying the debtor and thus makes it difficult to discharge the debts, the debtor may suspend the discharge or deposit the targeted matter. (see Contract Law of the PRC Article70, p.38) 


\section{MC: Article 70}

Where the obligee fails to notify the obligor of its separation, merger, or change of the domicile, thereby making it difficult for the obligor to perform its obligations, the obligor may suspend its performance or escrow the subject matter. (see Contract Law of the PRC Article70, p.12)

\subsubsection{Prepositional phrases}

Ex:

LPC: Article 369

The parties may stipulate the place and method of safekeeping. Except in case of emergency or in the interests of the depositor, the place and method for safekeeping may not be changed unilaterally. (see Contract Law of the PRC Article369, p.160)

MC: Article 369

The depository shall keep the deposit with due care. The parties may agree the place and manner of storage. The place and manner of storage may not be changed without authorization, except in an emergency situation or for the purpose of protecting the depositor's interests. (see Contract Law of the PRC Article369, p.55)

In this example article, both the LPC and MC combine both semantic and communicative translation theory and use prepositional phrases like "in case of", "in the interests of" and "for the purpose of". Using those prepositional phrases preserves the clarity and removes obscurities of the original text, and should be promoted in the legal documents translation.

\subsubsection{Passive voice}

Ex:

LPC: Article 10

The parties may, when making a contract, use written form, verbal form or any other form.

The written form shall be adopted if laws or administrative regulations so require. The written form shall be adopted if the parties so agree. (see Contract Law of the PRC Article10, p.10)

MC: Article 10

The parties may use written, oral or other forms in entering into a contract. A contract shall be in written form if the laws or administrative regulations so provide. A contract shall be concluded in written form if the parties so agree. (see Contract Law of the PRC Article10, p.2)

In Chinese, we do not often use passive voice; while in English, we employ this kind of voice frequently. Passive voice has its own advantage for us to translate texts, especially in legal documents, without unnecessarily demonstrating what they belong to, which is also known as impersonality. In contrast, combining both semantic and communicative translation theory, LPC is better than MC, because two passive voices are used orderly.

\subsubsection{Negative sentences}

Ex:

LPC: Article 95

If no time limit for exercising the right to dissolve is provided for by laws or by agreement of the parties, but the parties concerned does not exercise such right within a reasonable time after being urged by the other party, such right shall vanish. (see Contract Law of the PRC Article95, p.48)

MC: Article 95

Where neither the law stipulates nor the parties make an agreement upon the time limit to exercise the right to terminate the contract, and no party exercise it within a reasonable time period after being urged, the said right shall be extinguished. (see Contract Law of the PRC Article95, p.16)

Combining both semantic and communicative translation theory, I think, here sentential form "neither...nor..." is better than "does not", though both of the translations are fully translated.

\subsubsection{Conditional sentences}

When the present author analyzes Contract Law, there are many possible situations, exceptions 
and hypothesis. So the conditional sentences come across frequently. Like using the phrases "in the event of”, "where”, “when”, "if”, “assuming that”, "provided that”, "in order to”, "for the purpose of”, "save”, “except”, “unless”, "but for” and so on.

Ex:

LPC: Article 133

The ownership over a targeted matter is transferred upon the delivery of the targeted matter, unless the law provides otherwise or the parties stipulate otherwise. (see Contract Law of the PRC Article133, p.66)

MC: Article 133

The ownership of a subject matter shall be transferred upon the delivery of the object, except as otherwise stipulated by law or agreed upon by the parties. (see Contract Law of the PRC Article133, p.22)

Here, "unless" and "except" both are conditional clauses which can be acceptable semantically and communicatively. In this Contract Law, there are many articles used "unless" or "except" to express the provisionary clause for exceptions.

\section{Conclusion}

This thesis is about the research of a contrastive study of two versions of translation of Contract Law of the PRC from the perspective of Newmark's semantic and communicative translation.

Newmark once said: "communicative translation is social, concentrates on the message and the main force of the text, tends to be under-translate, simple, clear and brief, and is always written in a natural and resourceful way." (Newmark, 1988:97) All in all, Contract Law as one of laws formulated by the National People's Congress of the PRC to regulate people's behavior should be translated in accordance with the criterion of preciseness, conciseness, coherence, formalness and impersonality and so on. By comparing the two versions, on the one hand, both the LPC and MC have merits. In some articles LPC is better; in others MC is more appropriate. For example, precise and accurate translation of most terminologies; proper using of Archaic words, modal auxiliaries, prepositional phrases, passive voice, and conditional sentences are beneficial to attain preciseness, conciseness, formalness and impersonality. In summary, the two versions, to a certain extent, can both convey the meaning of the original Chinese version. However, on the other hand, there indeed exist some deficiencies. For instance, overusing the modal auxiliary "shall", unidiomatic manifestation of some legal terminologies, inappropriate using archaic and loan words, employing informal word to translate legal documents and not notifying the importance of nominalization and prepositional phrases, and so on. That means there still much room for the two versions to be perfect themselves.

When we try to translate legal documents which demand a special kind of translation method, we should bear in mind that mere semantic or communicative translation cannot fulfill the task of legal translating. Semantic translation attempts to restore the original and transfer all the text meaning and sentence structures to the target language as allowed, while, communicative translation commits itself to giving its second readers an understanding as close as possible to that obtained on the original readers by converting foreign elements into its own culture. So if we could appropriately combine them according to different situations, then maybe we could make up for their deficiencies.

As more and more people engaged in legal translation, the influences of China's legal system will eventually expand, and wake up to the whole world.

\section{Acknowledgement}

Fund Program: 2016 Research Project of Wuzhou University (Project Number: 2016C001) 


\section{References}

[1] Newmark, Peter. Approaches to Translation [M]. Oxford: Pergamon Press, 1981: 50-54.

[2] Nida, E. A. \& Jin Di, On Translation [M]. Beijing: China Translating and Publishing Corporation, 1984: 34-35.

[3] Sarcevic, Susan, New Approach to Legal Translation [M]. The Hague: Kluwer Law International, 1997: 12.

[4] Information on http://policy.mofcom.gov.cn/en/claw!fetch.html?id=e01581

[5] Chen Jiong. Several Problems in Legal Language Study. [J] Jiangnan College Academic Journal, 2000, (3): 14. (In Chinese)

[6] Chen Zhongcheng. Method of Legal Words Translation. [M]. Beijing: China Translation Corporation, 1998:47. (In Chinese)

[7] Contract Law of the PRC. [M]. Beijing: China Legal Publishing House, 1999. (In Chinese) 